practitioners. Further research should be directed to finding out why this is the case.

1 Dunnel K. Deaths among 15-44 year olds. Population Trends 1991;64:38-43. 2 Secretary of State for Health. The health of the nation: a strategy for health in England. London: HMSO, 1992.
3 Seager CP, Flood RA. Suicide in Bristol. Br F Psychiatry 1965;111:919-32. 4 Barraclough B, Bunch J, Nelson B, Sainsbury P. A hundred cases of suicide: clinical aspects. $\mathrm{Br} \mathcal{F}$ Psychiatry 1974;125:355-73.

5 Rutz W, Von Knorring L, Walinder J. Long term effects of an educational program for general practitioners given by the Swedish Committee for the program for general practitioners given by the Swedish Committee for the

(Accepted 21 May 1993)

\title{
Efficacy of hepatitis B vaccination: knowledge among clinical medical students
}

\section{B C Oates, A J Sidebottom, S R J Maxwell}

\section{Birmingham Medical} School and Department of Medicine, Queen Elizabeth Hospital, Birmingham B15 2TH

B C Oates, medical student

A J Sidebottom, medical student

S R J Maxwell, lecturer in

clinical pharmacology

Correspondence to: Dr Maxwell.

BMf 1993;307:301
Hepatitis B virus infection is a preventable cause of morbidity and mortality. Potential complications of infection are chronic hepatitis, cirrhosis, and hepatocellular carcinoma. In 1982 the first hepatitis B vaccine was introduced into the United Kingdom. As the prevalence of hepatitis B is relatively low in the United Kingdom a selective immunisation policy has been implemented, with high risk groups identified and targeted to receive the vaccine. Doctors are a well defined group who have an increased risk of hepatitis B virus infection through contact with patients and needlestick injuries. Autoinoculation is more likely to occur early in a medical career owing to inexperience, ${ }^{1}$ so it is appropriate to immunise doctors early in their training.

We monitored the progress of the vaccination programme for medical students at Birmingham Medical School, paying particular attention to the success rate of the vaccine and the students' knowledge of its protection and their responsibility in aftercare.

\section{Subjects, methods, and results}

At Birmingham Medical School all second year preclinical medical students receive a three injection course of hepatitis B vaccine (Engerix B) in a 0,1 , and 6 month schedule. Subsequently antibody titres are measured using the Amerlite system. ${ }^{2}$ Titres above 100 $\mathrm{IU} / \mathrm{ml}$ indicate an adequate response. ${ }^{3}$ All fourth year medical students $(n=146)$ were invited to fill in a confidential questionnaire relating to their hepatitis B immunisation. It asked: $(a)$ when and where they had received the vaccination course; $(b)$ whether or not they had completed the course; (c) how long they expected the immunity they had acquired would last; (d) whether their hepatitis B antibody titre had ever been measured; and (e) if so, what the titre was. One hundred and forty six completed questionnaires were returned $(100 \%)$ and the results were analysed.

Of the 146 students, five had not completed the vaccination course. None of these five had requested antibody titres. Ninety had arranged to have their antibody titre measured after completing the course. Among these 90, 21 (23\%) had antibody titres of less than $100 \mathrm{IU} / \mathrm{ml}$ and nine $(10 \%)$ had titres of less than $=10 \mathrm{IU} / \mathrm{ml}$. A response of over $100 \mathrm{IU} / \mathrm{ml}$ was achieved in $69(77 \%)$ of the students, although only 53 of these had a record of their actual titre. Fifty two (36\%) of the 146 students surveyed believed that the immunisation schedule they had received would offer lifelong protection.

\section{Comment}

About $1 \%$ of adult inpatients carry the hepatitis B virus, so effective immunisation for health care workers is important. Although many studies have shown a greater efficacy of the hepatitis $B$ vaccine than we found among these students, ${ }^{4}$ similar results are not uncommon. ${ }^{5}$ Ideally, vaccine recipients should be aware of the need to have their immunity checked by antibody titre measurements, thus allowing booster injections to be administered if required. We found, however, that two years after completing their vaccination programme $56(38 \%)$ of the students had failed to request this investigation. This suggested that many students were unaware of the risk of vaccine failure and consequent lack of protection. Also 52 $(36 \%)$ of those surveyed assumed that immunity to hepatitis B virus after vaccination would be life long. This lack of knowledge, combined with the $23 \%$ failure rate of the vaccine, might result in a significant occupational risk over many years.

It must remain the responsibility of every individual to ensure adequate immunity both after vaccination and at regular intervals throughout a career. However, preclinical medical students, who are inexperienced and often unaware of the risk of exposure to hepatitis B virus, should be offered education and counselling.

The occupational health department at Birmingham Medical School has now adopted a new protocol for hepatitis B immunisation for preclinical medical students. In future all students will have completed the vaccination course by the end of their first year of study. They will then receive a routine call up for antibody titre measurements, allowing any booster vaccinations to be undertaken before they start their clinical course. An alternative protocol might include the use of personal record cards documenting dates of immunisations, titre measurement, and recommendations for booster injections.

This report has highlighted potential deficiencies in the management of a student hepatitis B immunisation programme. We believe that the relatively high failure rate of vaccination and limited life span of immunity deserve further recognition among medical students.

We thank Mrs Wendy Hall, occupational health nurse, for her help with this project.

\footnotetext{
1 Gilson R. Hepatitis B vaccination: Who, when and why? Prescriber 1992;3 94-100.

2 Follett EAC. Amerlite anti-HBs as an alternative method for post vaccination testing. In: Enhanced luminescence: applications for hepatitis testing. Oxford: Medicine Publishing Foundation, 1990:32-5 (symposium series 28).

3 Hadler SC, Francis DP, Maynard JE, Thompson SE, Judson FN, Echenberg $\mathrm{DF}$, et al. Long term immunogenicity and efficacy of hepatitis $\mathrm{B}$ vaccine in homosexual men. N Engl f Med 1986;315:209-14.

4 Zanetti AR, Tanzi E, Pozzi A, Romano L, Bergamini F. Yeast-derived hepatitis $B$ vaccine in dental students. A three year follow-up study. Vaccine $B$ vaccine in
$1990 ; 8: 205-8$.

5 Westmoreland D, Player V, Heap DC, Hammond A. Immunisation against hepatitis B. What can we expect? Epidemiol Infect 1990;104:499-509.
}

(Accepted 15 April 1993) 